\title{
Maternal food consumption during pregnancy and asthma, respiratory and atopic symptoms in 5-year-old children
}

\author{
S M Willers, G Devereux, L C A Craig, G McNeill, A H Wiiga, W Abou El-Magd, S W Turner, P J Helms, \\ A Seaton
}

See end of article for authors' affiliations

......................

Correspondence to:

S M Willers, MSc, Institute

for Risk Assessment

Sciences, Division of

Environmental

Epidemiology, Utrecht

University, P'O Box 80178,

3508 TD Utrecht, The

Netherlands; S.Willers@

iras.uu.nl

Received 30 October 2006

Accepted 15 February 2007

Published Online First

27 March 2007

\begin{abstract}
Background: Associations between maternal vitamin $E$, vitamin $D$ and zinc intakes during pregnancy and asthma, wheeze and eczema in 5-year-old children have previously been reported. A study was undertaken to investigate whether maternal intake of specific foods during pregnancy is associated with asthma and allergic outcomes in the same children.

Methods: A longitudinal birth cohort study was conducted in 1924 children born to women recruited during pregnancy. Maternal diet during pregnancy was assessed by food frequency questionnaire (FFQ). Cohort children were followed up at 5 years by symptom questionnaire and FFQ. Food groups of interest were fruit, vegetables, fruit juice, whole grain products, fish, dairy products and fat spreads. Trends across outcome groups defined by level of food intake are presented.

Results: 1253 children participated at 5 years and maternal FFQ data were available for 1212 . No consistent associations were found between childhood outcomes and maternal intake of the analysed foods except for apples and fish. Maternal apple intake was beneficially associated with ever wheeze (OR highest vs lowest tertile $0.63,95 \% \mathrm{Cl} 0.42$ to 0.95 ), ever asthma (OR $0.54,95 \% \mathrm{Cl} 0.32$ to 0.92 ) and doctorconfirmed asthma (OR $0.47,95 \% \mathrm{Cl} 0.27$ to 0.82 ) in the children. Maternal fish consumption was beneficially associated with doctor-confirmed eczema (OR $\geqslant 1$ / week vs never $0.57,95 \% \mathrm{Cl} 0.35$ to 0.92 ). Conclusion: There was no evidence for associations between maternal intake of most foods during pregnancy and asthma, respiratory and allergic outcomes in 5-year-old children, except for apples and fish. Consumption of apples and fish during pregnancy may have a protective effect against the development of childhood asthma and allergic disease.
\end{abstract}

interest are those that have previously been reported to be associated with asthma or atopic disease in adults and children (citrus fruit, apples, fruit juices, vegetables, fish, oily fish, dairy products and whole grain products). Beneficial associations in children have been reported for fruit, ${ }^{8-10}$ fruit juice, ${ }^{11}$ vegetables, ${ }^{8}$ fish, ${ }^{912}$ oily fish, ${ }^{12}$ full fat dairy products ${ }^{13}$ and whole grain products, ${ }^{13}{ }^{14}$ while harmful associations have been reported for margarine and salt. ${ }^{15} 16$

The advantages of studying foods are that they contain a mixture of micronutrients that may contribute more than the sum of their parts, and that associations with micronutrients that may be currently unrecognised or not easily quantifiable can be examined. In addition, an evaluation of the associations with nutrients and foods will guide any future intervention study that could be the basis for a public health intervention to prevent asthma and atopic disease by dietary intervention.

\section{METHODS}

\section{Study population and study design}

Details of the study design have been published previously. ${ }^{2-4}$ Briefly, 2000 healthy pregnant women were recruited between October 1997 and April 1999 irrespective of their asthma/atopic status while attending antenatal clinics at Aberdeen Maternity Hospital at a median gestational age of 12 weeks. Apart from expected slight biases, the recruited women were representative of the local obstetric population. ${ }^{4}$ At enrolment, the women completed an interviewer-administered questionnaire and atopic status was ascertained by skin prick testing (ALK-UK, Hungerford, UK). Although the ensuing cohort of singleton children was followed up at 1, 2 and 5 years, this report is limited to the 5 year follow-up.

Abbreviations: $\mathrm{FEV}_{1}$, forced expiratory volume in $1 \mathrm{~s} ; \mathrm{FFQ}$, food frequency questionnaire 


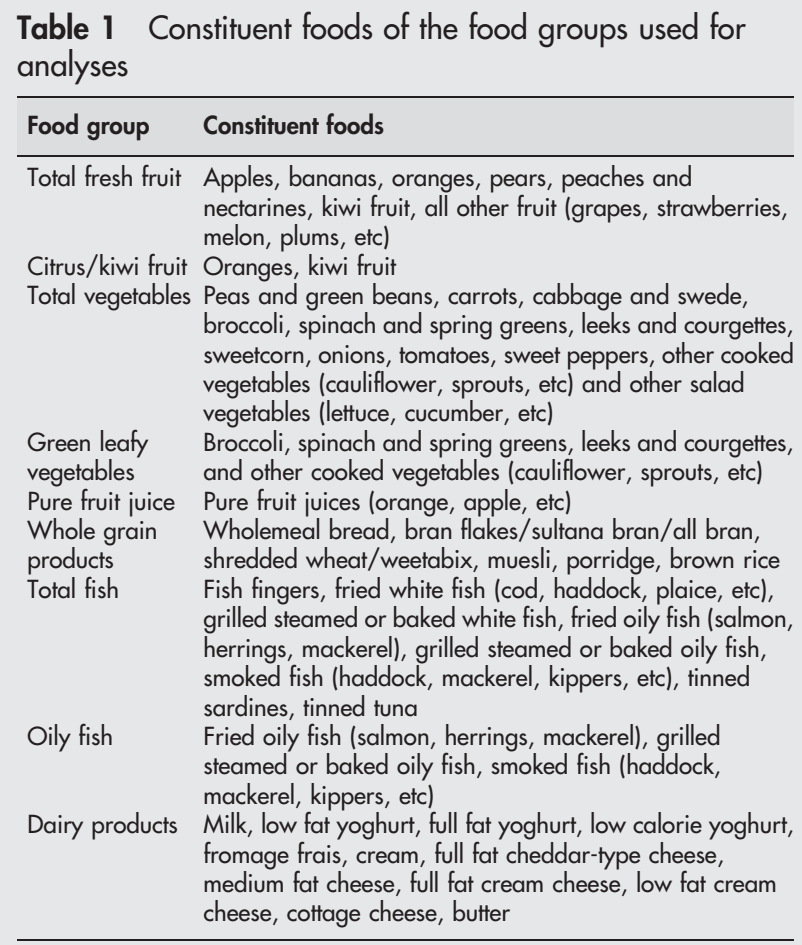

\section{Children's health outcomes}

At 5 years a questionnaire based on the International Study of Asthma and Allergy in Childhood (ISAAC) core questions on symptoms of asthma, allergic rhinitis and atopic eczema was sent to all participating families with up to two reminders. ${ }^{2}{ }^{417}$ The main questionnaire-derived outcomes of interest were "Has your child ever wheezed?" (with supplementary questions about wheeze in the last year), "Has your child ever suffered from asthma?", "Has this been confirmed by a doctor?" and "Has your child received treatment for asthma in the past 12 months?". Similar questions enquired about eczema and hay fever. Current asthma was defined as asthma and wheeze in the previous year.

Responding parents were also invited to complete a food frequency questionnaire (FFQ) pertaining to the study child's current diet and to bring the child to the hospital for an assessment including spirometry, skin prick testing and measurement of exhaled nitric oxide. Originally, measurement of bronchodilator response and exhaled nitric oxide were not included in the study protocol but were introduced for the last 510 and 262 children, respectively. ${ }^{2}$ Details of the hospital assessment have been published previously. ${ }^{2}$ Spirometry was measured using a pneumotachograph (Spirotrac IV Version 4.22, Vitalograph, Maids Moreton, UK). Bronchodilator response was expressed as the percentage change in forced expiratory volume in $1 \mathrm{~s}\left(\mathrm{FEV}_{1}\right) 15 \mathrm{~min}$ after inhalation of $400 \mu \mathrm{g}$ salbutamol. Atopy was defined as at least one positive skin prick test response to the allergens cat, timothy grass, egg and house dust mite (ALK-UK, Hungerford, UK). A positive response was defined as a mean wheal diameter of $3 \mathrm{~mm}$ or more than the negative control. A NIOX analyser (Aerocrine$\mathrm{AB}$, Solna, Sweden) was used to measure exhaled nitric oxide. Parents gave their written consent and the Grampian research ethics committee approved the study.

\section{Assessment of maternal diet during pregnancy}

Maternal diet during pregnancy was assessed by a semiquantitative FFQ (Version 5.4 of the Scottish Collaborative Group FFQ) mailed at 32 weeks gestation. ${ }^{18}$ This FFQ consisted of 150 items divided into 20 food groups. Mothers were asked to describe how much of each food on the list they had eaten in the previous 2-3 months. Categories for the frequency of the foods eaten were R (rarely or never), $M$ (once or twice a month) and the categories 1-7 days per week. Further to this categorisation, the amount of each food consumed ranged from 1 to $5+$ measures per day. For each food a measure was specified, which was usually a small unit (eg, slice) or household measure (eg, tablespoon) rather than a typical portion. In order to convert to a numerical scale, the frequency value $R$ was replaced by 0 and the value $M$ by 0.375 . The number of measures per day was multiplied by the number of days per week to obtain the total measures per week. The food groups of interest in this study were total fruit, citrus/kiwi fruit, apples, total vegetables, green leafy vegetables, pure fruit juice, whole grain products, total fish, total oily fish, total fat from dairy products and exclusive butter versus margarine/low fat spread used as spread. The individual foods included in the food groups are described in table 1.

The total number of measures per week was divided into tertiles for total fruit, citrus/kiwi fruit, apples, total vegetables, green leafy vegetables, pure fruit juice, whole grain products and into the categories never, less than once a week, and once or more a week for total fish and total oily fish. To facilitate extrapolation to the general population, subdivisions of food intakes into tertiles were derived from all of the women completing the FFQ and not merely those responding at 5 years.

\section{Assessment of childhood diet at age 5}

Parents were invited to complete an FFQ to assess the study child's dietary intake over the previous 3 months. Version $\mathrm{Cl}$ of the Scottish Collaborative Group FFQ was used. This is a 121 item semi-quantitative instrument based on the questionnaire used for the mothers in pregnancy, but has been modified for use in pre-school children aged $3-5$ years by simplifying the response choices and changing the food list and portion sizes to be appropriate for pre-school children. Validity for specific nutrients in this age group has been reported. ${ }^{19}$

\section{Statistical analyses}

All analyses were carried out using SPSS Version 13.0 (SPSS Inc, Chicago, USA). Mantel-Haenszel odds ratios were used to assess the univariate associations between childhood outcomes and food groups, while ordinary least squared multiple logistic regression analysis using forced choice selection to adjust for covariates was used for the multivariate analyses. Covariates in the multivariate model were maternal age, paternal social class, maternal age of leaving full time education, maternal smoking during pregnancy, maternal asthma (for wheeze, asthma, and hay fever outcomes), maternal atopy, child's birth weight, child's sex, presence of older siblings, breast feeding and smoking in the child's home at 5 years.

\section{RESULTS}

\section{Study population and prevalence of respiratory and allergic symptoms}

Two thousand pregnant women were recruited, of whom 1751 completed the FFQ. There were 1924 live singleton births. Symptom questionnaire data at age 5 were obtained for 1253 children and maternal FFQ data were available for 1212 of these. FFQ, spirometry, bronchodilator response, skin prick test and exhaled nitric oxide results were available for 1120, 639, 238, 700 and 167 children, respectively. Maternal intake of the food groups during pregnancy and for those responding at 5 years is shown in table 2 .

Although the mothers responding to the 5 year questionnaire were more likely to eat fruit, citrus/kiwi fruit, green leafy 
Table 2 Maternal and dietary characteristics of mothers responding to the 5 year questionnaire

\begin{tabular}{llll}
\hline & $\begin{array}{l}\text { Mothers completing FFQ } \\
\text { during pregnancy } \\
\text { (n=1751) }\end{array}$ & $\begin{array}{l}\text { Respondent mothers } \\
\text { at age 5 } \\
\text { (N=1212) }\end{array}$ & p Value*
\end{tabular}

$\mathrm{FFQ}$, food frequency questionnaire.

*Responders at age 5 vs non-responders.

†Non-parametric test.

vegetables, whole grain products and oily fish during pregnancy than non-responding mothers, the magnitude of the differences was small $(<10 \%)$. Responding mothers also had significantly lower energy intake and a lower intake of fat from dairy products. The characteristics of the mothers and children who did or did not attend the hospital for assessment has been published previously. ${ }^{2}$ Briefly, the mothers and children who attended for hospital assessment were broadly representative of those responding to the questionnaire, with any significant differences being of small magnitude. ${ }^{2}$ The characteristics of the mothers and their children and the prevalence of asthma and atopic symptoms in both are shown in table 3.

\section{Associations between maternal diet during pregnancy and respiratory and allergic symptoms in children aged 5 years}

Recruitment data were available for all 1253 mother-child pairs but, because of incomplete ascertainment at the ensuing data collection points, the number of mother-child pairs with complete datasets included in the final multivariate analyses was less than the total number of respondents at age 5 $(\mathrm{n}=1253)$. For the 1253 mother-child pairs, FFQ data at 32 weeks gestation were available for 1212, birth weight data were available for 1200, and breast feeding and maternal age of leaving full time education data collected at 1 year were available for 1176 and 1113, respectively. Incomplete mother-child pairs appeared to be random, and those with complete datasets did not differ significantly from those with incomplete datasets for all the variables included in the multivariate analyses.

No consistent linear associations were found between maternal intake of total fruit, citrus/kiwi fruit, total vegetables, green leafy vegetables, fruit juice, whole grain products, fat from dairy products or butter versus margarine/low fat spread use and respiratory or atopic outcomes in the 5-year-old children, nor were there consistent associations between maternal intake of food groups and spirometry, atopic sensitisation, bronchodilator response or exhaled nitric oxide.

Table 3 Characteristics of mothers and children and prevalence of respiratory and atopic symptoms

\begin{tabular}{llll}
\hline Maternal characteristics & $\mathrm{n}=1253$ & Children's characteristics & $\mathrm{n}=1253$ \\
\hline Age at recruitment (mean, 95\% Cl) & $29.9(29.6$ to 30.2) & Male (\%) & $630(50.3 \%)$ \\
Partner's social class (\% non-manual) & $767(61.2 \%)$ & Birth weight (g) (mean, 95\% Cl) & $3458(3426$ to 3489) \\
Age left full time education (median, IQR) & $18.5(16.0-21.0)$ & Ever breast fed & $74.3 \%$ \\
FFQ returned & $1212(96.7 \%)$ & & \\
Smoking during pregnancy & $288(23.0 \%)$ & & $162(12.9 \%)$ \\
Prevalence of respiratory and allergic symptoms & & Wheeze in last 12 months & \\
Ever wheezed & $415(33.1 \%)$ & Wheeze in absence of cold in last 12 months & $84(6.7 \%)$ \\
Current asthma & $125(10.0 \%)$ & Ever wheezed & $253(20.2 \%)$ \\
Ever had asthma & $189(15.1 \%)$ & Asthma and wheeze in last 12 months & $107(8.5 \%)$ \\
Asthma medication & $123(9.8 \%)$ & Doctor confirmed asthma & $145(11.6 \%)$ \\
Ever had hay fever & $313(25.0 \%)$ & Ever had asthma & $156(12.5 \%)$ \\
Ever had eczema & $213(17.0 \%)$ & Doctor confirmed eczema & $380(30.4 \%)$ \\
Atopic sensitisation & $448(35.8 \%)$ & Current eczema treatment & $191(15.3 \%)$ \\
& & Ever had eczema & $406(32.4 \%)$ \\
& & Doctor confirmed hay fever & $68(5.4 \%)$ \\
& & Current hay fever medication & $44(3.5 \%)$ \\
& & Ever had hay fever & $111(8.9 \%)$ \\
& & Atopic sensitisation (n=699) & $149(21.3 \%)$ \\
\hline
\end{tabular}

$F F Q$, food frequency questionnaire; IQR, interquartile range. 
Table 4 Associations between maternal apple consumption and childhood wheeze and asthma at age 5 years

\begin{tabular}{|c|c|c|c|c|c|}
\hline \multirow[b]{3}{*}{ Childhood outcome, n (\%) } & \multirow[b]{3}{*}{$\mathbf{N}$} & \multicolumn{3}{|c|}{ Maternal apple consumption } & \multirow[b]{3}{*}{$p$ trend } \\
\hline & & \multirow{2}{*}{$\begin{array}{l}\text { T1 (0-1/week) } \\
\mathrm{n}=398 \\
\text { OR }(95 \% \mathrm{CI})\end{array}$} & \multirow{2}{*}{$\begin{array}{l}\text { T2 (1-4/week) } \\
n=427 \\
\text { OR }(95 \% \mathrm{Cl})\end{array}$} & \multirow{2}{*}{$\begin{array}{l}\text { T3 (>4/week) } \\
n=384 \\
\text { OR }(95 \% \mathrm{Cl})\end{array}$} & \\
\hline & & & & & \\
\hline \multicolumn{6}{|l|}{$\begin{array}{l}\text { Wheeze in last } 12 \text { months, } \\
n=162(12.9 \%)\end{array}$} \\
\hline Univariate & 1003 & 1 & 1.09 (0.69 to 1.67$)$ & 0.61 (0.37 to 1.01$)$ & 0.066 \\
\hline Multivariate* & 1003 & 1 & 1.08 (0.68 to 1.71$)$ & $0.67(0.40$ to 1.13$)$ & 0.156 \\
\hline \multirow{2}{*}{\multicolumn{6}{|c|}{ Wheeze without cold in last }} \\
\hline & & & & & \\
\hline Univariate & 1003 & 1 & 1.32 (0.72 to 2.43 ) & $0.64(0.31$ to 1.35$)$ & 0.286 \\
\hline Multivariate* & 1003 & 1 & $1.27(0.67$ to 2.43$)$ & 0.70 (0.32 to 1.51$)$ & 0.411 \\
\hline \multicolumn{6}{|c|}{ Ever wheezed, $n=253$ (20.2\%) } \\
\hline Univariate & 999 & 1 & 0.86 (0.60 to 1.23 ) & $0.59(0.40$ to 0.88$)$ & 0.009 \\
\hline Multivariate* & 999 & 1 & 0.85 (0.58 to 1.24 ) & $0.63(0.42$ to 0.95$)$ & 0.029 \\
\hline \multicolumn{6}{|l|}{$\begin{array}{l}\text { Asthma and wheeze in last } \\
12 \text { months } n=107 \text { (8.5\%) }\end{array}$} \\
\hline Univariate & 998 & 1 & $1.02(0.60$ to 1.73$)$ & 0.55 (0.29 to 1.03$)$ & 0.072 \\
\hline Multivariate ${ }^{*}$ & 998 & 1 & 1.03 (0.59 to 1.80 ) & $0.60(0.31$ to 1.16$)$ & 0.148 \\
\hline \multicolumn{6}{|l|}{$\begin{array}{l}\text { Doctor confirmed asthma, } \\
n=145(11.6 \%)\end{array}$} \\
\hline Univariate & 998 & 1 & $0.87(0.56$ to 1.36$)$ & $0.46(0.27$ to 0.78$)$ & 0.005 \\
\hline Multivariate* & 998 & 1 & 0.83 (0.52 to 1.32 ) & $0.47(0.27$ to 0.82$)$ & 0.008 \\
\hline \multicolumn{6}{|l|}{$\begin{array}{l}\text { Ever had asthma, } \\
n=156(12.5 \%)\end{array}$} \\
\hline Univariate & 998 & 1 & 0.90 (0.58 to 1.38$)$ & $0.52(0.31$ to 0.86$)$ & 0.013 \\
\hline Multivariate* & 998 & 1 & $0.86(0.54$ to 1.36$)$ & 0.54 (0.32 to 0.92$)$ & 0.026 \\
\hline
\end{tabular}

*Adjusted for maternal age of leaving full time education, paternal social class, maternal age, maternal smoking during pregnancy, smoking in the home during childhood, energy intake, maternal asthma, maternal atopy, birth weight, presence of older siblings, sex of child and breastfeeding.

Beneficial associations were found between maternal apple intake and the childhood outcomes of ever wheezed, ever had asthma and doctor confirmed asthma at age 5, with significant linear trends (table 4).

Maternal apple intake was not associated with childhood eczema and hay fever or atopic sensitisation. However, beneficial associations were found between maternal total fish intake and doctor confirmed eczema and currently treated eczema (table 5), and between maternal oily fish intake and doctor confirmed hay fever (table 6).

There was a significant beneficial association between higher maternal oily fish intake ( $\geqslant 1$ portion a week) and ever having hay fever, but the association did not show a significant linear trend $(\mathrm{p}=0.159$, table 6$)$.
Inclusion of maternal supplement use during pregnancy did not alter the magnitude or significance of the associations between maternal food intake and outcomes in 5-year-old children.

Association between the children's diet and respiratory and allergic symptoms at age 5 years

Maternal diet during pregnancy and the child's diet at age 5 were weakly but significantly positively correlated. Kendall's tau-b statistics were $0.21 \quad(\mathrm{p}<0.001)$ for the child's and maternal total fruit consumption, $0.15(\mathrm{p}<0.001)$ for apple consumption, and $0.20(\mathrm{p}<0.001)$ and $0.26(\mathrm{p}<0.001)$ for total fish and oily fish consumption, respectively. Despite this, we found no consistent associations between the children's intake

Table 5 Associations between maternal total fish consumption and childhood eczema at age 5 years

\begin{tabular}{|c|c|c|c|c|c|}
\hline \multirow[b]{3}{*}{ Childhood outcome, n (\%) } & \multirow[b]{3}{*}{$\mathbf{N}$} & \multicolumn{3}{|c|}{ Maternal total fish consumption } & \multirow[b]{3}{*}{$p$ trend } \\
\hline & & \multirow{2}{*}{$\begin{array}{l}\text { Never } \\
n=107 \\
\text { OR }(95 \% \mathrm{Cl})\end{array}$} & \multirow{2}{*}{$\begin{array}{l}<1 / \text { week } \\
n=255 \\
\text { OR }(95 \% \mathrm{Cl})\end{array}$} & \multirow{2}{*}{$\begin{array}{l}\geqslant 1 / \text { week } \\
n=831 \\
\text { OR }(95 \% \mathrm{Cl})\end{array}$} & \\
\hline & & & & & \\
\hline \multicolumn{6}{|l|}{$\begin{array}{l}\text { Doctor confirmed eczema } \\
n=380(30.4 \%)\end{array}$} \\
\hline Univariate & 979 & 1 & 0.77 (0.46 to 1.28$)$ & $0.60(0.38$ to 0.96$)$ & 0.016 \\
\hline Multivariate* $^{*}$ & 979 & 1 & 0.79 (0.47 to 1.32 ) & 0.57 (0.35 to 0.92$)$ & 0.008 \\
\hline \multicolumn{6}{|l|}{$\begin{array}{l}\text { Current eczema medication } \\
\mathrm{n}=191(15.3 \%)\end{array}$} \\
\hline Univariate & 982 & 1 & $0.85(0.45$ to 1.61$)$ & 0.67 (0.38 to 1.19$)$ & 0.111 \\
\hline Multivariate* & 982 & 1 & $0.88(0.46$ to 1.67$)$ & 0.58 (0.32 to 1.06$)$ & 0.028 \\
\hline \multicolumn{6}{|l|}{$\begin{array}{l}\text { Ever had eczema } \\
n=406(32.4 \%)\end{array}$} \\
\hline Univariate & 983 & 1 & 0.88 (0.53 to 1.47$)$ & $0.73(0.47$ to 1.16$)$ & 0.111 \\
\hline Multivariate* & 983 & 1 & 0.91 (0.54 to 1.53 ) & $0.68(0.43$ to 1.10$)$ & 0.050 \\
\hline
\end{tabular}

*Adjusted for maternal age of leaving full time education, paternal social class, maternal age, maternal smoking during pregnancy, smoking in the home during childhood, energy intake, maternal atopy, birth weight, presence of older siblings, sex of child and breastfeeding. 
Table 6 Associations between maternal oily fish consumption and childhood hay fever at age 5 years

\begin{tabular}{|c|c|c|c|c|c|}
\hline \multirow[b]{3}{*}{ Childhood outcome, n (\%) } & \multirow[b]{3}{*}{$\mathbf{N}$} & \multicolumn{3}{|c|}{ Maternal oily fish consumption } & \multirow[b]{3}{*}{$p$ trend } \\
\hline & & \multirow{2}{*}{$\begin{array}{l}\begin{array}{l}\text { Never } \\
n=629\end{array} \\
\text { OR }(95 \% \mathrm{Cl})\end{array}$} & \multirow{2}{*}{$\begin{array}{l}<1 / \text { week } \\
\mathrm{n}=414 \\
\text { OR }(95 \% \mathrm{Cl})\end{array}$} & \multirow{2}{*}{$\begin{array}{l}\geqslant 1 / \text { week } \\
n=161 \\
\text { OR }(95 \% \mathrm{Cl})\end{array}$} & \\
\hline & & & & & \\
\hline \multicolumn{6}{|l|}{$\begin{array}{l}\text { Doctor confirmed hay fever } \\
n=68(5.4 \%)\end{array}$} \\
\hline Univariate & 990 & 1 & 0.57 (0.31 to 1.08$)$ & 0.20 (0.05 to 0.85$)$ & 0.006 \\
\hline Multivariate $^{*}$ & 990 & 1 & 0.66 (0.34 to 1.28$)$ & 0.28 (0.06 to 1.19$)$ & 0.043 \\
\hline \multicolumn{6}{|l|}{$\begin{array}{l}\text { Current hay fever medication } \\
n=44(3.5 \%)\end{array}$} \\
\hline Univariate & 988 & 1 & 1.08 (0.53 to 2.22$)$ & 0.20 (0.03 to 1.53$)$ & 0.226 \\
\hline Multivariate* & 988 & 1 & $1.02(0.48$ to 2.20$)$ & 0.19 (0.02 to 1.48$)$ & 0.194 \\
\hline \multicolumn{6}{|l|}{$\begin{array}{l}\text { Ever had hay fever } \\
\mathrm{n}=111(8.9 \%)\end{array}$} \\
\hline Univariate & 988 & 1 & 1.11 (0.70 to 1.75$)$ & $0.38(0.15$ to 0.98$)$ & 0.155 \\
\hline Multivariate* & 988 & 1 & 1.11 (0.68 to 1.82$)$ & $0.37(0.14$ to 0.98$)$ & 0.159 \\
\hline
\end{tabular}

of apples, total fish or oily fish and respiratory or allergic symptoms at age 5 years.

\section{DISCUSSION}

This study investigated associations between maternal intake of different food groups during pregnancy and symptoms of asthma and atopy in children. There was no evidence of associations between asthma, respiratory or atopic outcomes in 5 -year-old children and maternal intakes of total fruit, citrus/ kiwi fruit, total vegetables, green leafy vegetables, fruit juice, whole grain products, fat from dairy products or butter versus margarine/low fat spread use. However, we have shown beneficial associations between maternal apple intake and childhood wheeze and asthma, and between maternal fish intake and childhood eczema and hay fever. There are some reports of beneficial effects of maternal fish consumption and maternal fish oil supplementation during pregnancy on childhood asthma and neonatal cord blood mononuclear cell response ${ }^{2021}$ but, to our knowledge, our finding of the protective effects of maternal apple consumption during pregnancy on childhood wheeze and asthma is new.

In this cohort we have reported beneficial associations between maternal vitamin E intake during pregnancy and cord blood mononuclear cell responses at birth, ${ }^{3}$ wheeze at age 2 years ${ }^{4}$ and wheeze and asthma at age 5 years. ${ }^{2}$ We have also found beneficial associations between maternal zinc intake during pregnancy and asthma and eczema in children at the age of 5 years, and between maternal vitamin D intake and wheeze in children at age 5 years. ${ }^{25}$ One of the aims of this study was to investigate whether these associations with maternal nutrient intakes could be a consequence of associations with individual foods rich in one or several of these nutrients, with obvious implications for a potential dietary intervention during pregnancy. It would seem that the associations reported here with maternal intake of apples and fish are insufficient to account for the associations with vitamin E, vitamin D and zinc because, in the UK, apples and fish provide less than $10 \%$ of dietary vitamin $\mathrm{E}$ and zinc intakes in women of this age group. In addition, the pattern of associations between vitamin E, vitamin D, zinc and childhood respiratory and allergic outcomes differed from those in the present study. In the UK there is no single major dietary source of vitamin $\mathrm{E}$ in women aged 25-49 years, with intake being evenly distributed between fat spreads (15\%), cereals/cereal products $(10 \%)$, potatoes/potato snacks (12-14\%), vegetables
(16-17\%) and meat/meat products (10\%). ${ }^{22}$ In the present study the absence of any association between the usual dietary sources of vitamin E and respiratory outcomes suggests that the associations with vitamin $\mathrm{E}$ in a previous report ${ }^{2}$ were unlikely to represent associations with other nutrients commonly found in foods containing vitamin $\mathrm{E}$.

The present study suggests beneficial associations between maternal apple intake during pregnancy and wheeze and asthma at age 5 years. The evidence from other observational studies on children's diet and respiratory and atopic symptoms is relatively consistent, showing beneficial effects of fruit and vegetable intake on indicators of asthma..$^{8-11}$ However, it is not clear whether these effects can be attributed to specific nutrients or that a high intake of fruit and vegetables is an indicator of a healthier lifestyle. The specific association found with apples in this study-and not with total fruit, citrus, fruit juice or vegetable consumption-suggests an effect specific to apples, possibly because of their phytochemical content such as flavonoids. Flavonoids are polyphenolic compounds with powerful antioxidant capacities and are associated with reduced risks of several diseases including asthma and chronic obstructive pulmonary disease. ${ }^{23-25}$ Intake of apples as a significant source of flavonoids and other polyphenols has been beneficially associated with asthma, bronchial hypersensitivity and lung function in adults. ${ }^{24}{ }^{26-28}$ These effects are usually ascribed to the strong antioxidant capacities of apples, although there is also evidence that some polyphenolic compounds can influence cytokine gene expression by Th cells, promoting the secretion of the Thl cytokine interferon $\gamma$ and inhibiting secretion of the Th2 cytokine interleukin-4. ${ }^{29}$ However, there is a lack of epidemiological evidence on the relation between the intake of flavonoids or specific flavonoidrich foods and asthma or allergy in children. Although the consumption of total fresh fruit has increased in recent years, apple consumption in the UK fell from $207 \mathrm{~g} /$ person/day in 1974 to $173 \mathrm{~g} /$ person/day in 2004/5. ${ }^{30}$ It has also been suggested that the mineral content of fruit and vegetables declined between 1940 and 1991. ${ }^{31}$ This could be the consequence of changes in cultivation, the use of fertilisers and the choice of fruit species that can be more easily harvested or stored.

The observation of beneficial associations between maternal total and oily fish consumption and current eczema and ever hay fever at age 5 years, respectively, is consistent with earlier observations. ${ }^{20}{ }^{21}$ Dunstan et $a l^{21}$ examined the effect of fish oil supplementation during pregnancy on early developing 
immune responses and clinical outcomes in infants predisposed to allergic disease. Neonates born to mothers supplemented with fish oil tended to have lower cord blood mononuclear cell cytokine responses to allergens and, at l year of age, significantly less severe disease if they had atopic dermatitis. Salam et $a^{20}$ studied the association between maternal fish consumption during pregnancy and childhood asthma. They found that maternal oily fish consumption at least monthly was significantly protective for persistent asthma in 5-year-old children. Other epidemiological evidence on the effect of fish intake or fish oil supplementation on asthma or allergic diseases provided by observational and intervention studies in children is inconsistent. ${ }^{32}{ }^{33}$ It is therefore more likely that the time window for n-3 polyunsaturated fatty acids to have an effect on immune regulation and subsequent asthma and atopic disease is indeed in fetal life, and that effects are limited once allergic immune responses are established. ${ }^{21}$

Originally, the study population of 2000 pregnant women was demographically very similar to the local obstetric population. ${ }^{4}$ In this study there was some evidence of response bias due to the loss to follow-up with time. Participating mothers were of higher socioeconomic status and had slightly higher consumption of fruit, green leafy vegetables, whole grain products and fish and had fewer respiratory symptoms. ${ }^{2}$ An analysis of the wheezing symptoms of the children whose mothers responded at 2 years but not at 5 years indicated that the children with no data at 5 years were more likely to have wheezed at 2 years (not shown). This type of response bias often plays a role in cohort studies because it is known that subjects with poorer socioeconomic status and lifestyle (lower educational level, poorer diet, smoking, etc) are more difficult to trace, and that people who suffer poor health during the follow-up period are prone to attrition. ${ }^{34}$ However, due to this type of bias, it is more likely that the observed associations in this study are underestimated than overestimated; for instance, improved ascertainment at 5 years would have resulted in a larger proportion of wheezy children with low maternal apple consumption, which would make the observed associations between maternal apple consumption and childhood asthma/wheezing symptoms stronger (in this case odds ratios closer to zero). A limitation of FFQ-derived estimates is that they are susceptible to dietary misreporting which leads to dietary misclassification of intake and/or portion sizes. Usually this misclassification is random and it also weakens rather than augments the associations. To avoid multiple hypothesis testing we chose a restricted number of food groups based on our previous findings in this cohort and earlier reported associations, ${ }^{13}{ }^{14} 27$ the lipid hypothesis $^{35}$ and antioxidant hypothesis. ${ }^{36}$ It is possible that the associations reported could be a consequence of the number of analyses performed. However, we consider this is unlikely because some of the associations were highly significant and the associations were clustered with food groups that have previously been associated with similar outcomes in children and adults.

The predominance of associations between maternal food intakes and doctor-diagnosed outcomes raises the possibility of ascertainment bias, whereby mothers more conscious of health issues were both more likely to follow dietary advice to eat healthily and more likely to take their unwell children to the doctor to receive a formal diagnosis. Such ascertainment bias seems unlikely because it predicts that maternal apple consumption should be adversely associated with childhood doctor-diagnosed conditions-the opposite to what we report.

The observed associations with maternal food intake during pregnancy were independent of the childhood diet because inclusion of children's apple and fish consumption in the models did not change the results, despite maternal and childhood diet being weakly correlated.
Published cross-sectional surveys of children have reported associations between the dietary intake of citrus, kiwi fruit and vegetables and indicators of asthma, ${ }^{8-10}$ but the present study failed to show any consistent associations between the food intake of children aged 5 years and respiratory and atopic symptoms. The children in the present study were younger than those participating in previous studies (6-11 years), and this may account for the disparity between this and previous studies. In the present study it would appear that, until at least the age of 5 years, maternal diet during pregnancy is more influential on respiratory health than childhood diet. Further follow-up of this birth cohort will be required to determine whether the associations with maternal diet decline in older children, and whether maternal and childhood diets interact in older children.

The associations between maternal apple consumption and asthma and symptoms could represent effects on airway and immune development, while the associations between maternal (oily) fish consumption and eczema and hay fever suggest effects on Th cell differentiation, ${ }^{37}$ yet no associations were found with lung function measures, exhaled nitric oxide and atopic sensitisation. This could reflect a loss of power due to the smaller number of children who underwent spirometric or skin prick tests.

The results of this cohort study indicate that there were no consistent linear associations between maternal intake of total fruit, citrus/kiwi fruit, total vegetables, green leafy vegetables, fruit juice, whole grain products, fat from dairy products or butter versus margarine/low fat spread use during pregnancy and asthma, respiratory and atopic outcomes in 5-year-old children. We did, however, find some evidence for protective effects of maternal apple and fish consumption. Thus, in addition to maternal intake of vitamin $\mathrm{E}$, vitamin $\mathrm{D}$ and zinc during pregnancy, ${ }^{2-5}$ maternal consumption of apples and fish during pregnancy may reduce the risk of children developing asthma or atopic disease. If these results are confirmed, recommendations on dietary modification during pregnancy may help to prevent childhood asthma and allergy.

\section{ACKNOWLEDGEMENTS}

The authors acknowledge the GA ${ }^{2}$ LEN European Network of Excellence on Global Allergy and Asthma for the fellowship grant that made exchange between IRAS, Utrecht University and the DEOM, University of Aberdeen possible.

\section{Authors' affiliations}

S M Willers, Institute for Risk Assessment Sciences (IRAS), Division of Environmental Epidemiology, Utrecht University, Utrecht, The Netherlands S M Willers, A H Wijga, Centre of Prevention and Health Services Research, The National Institute of Public Health and the Environment (RIVM), Bilthoven, The Netherlands

G Devereux, L C A Craig, G McNeill, W Abou El-Magd, A Seaton, Department of Environmental and Occupational Medicine, University of Aberdeen, Aberdeen, UK

G McNeill, S W Turner, P J Helms, Department of Child Health, University of Aberdeen, Aberdeen, UK

This study was made possible by support from Asthma UK (grant 02/017). Competing interests: None.

\section{REFERENCES}

1 Warner JO. The early life origins of asthma and related allergic disorders. Arch Dis Child 2004;89:97-102.

2 Devereux G, Turner SW, Craig LCA, et al. Reduced maternal vitamin E intake during pregnancy is associated with asthma in 5-year-old children. Am J Respir Crit Care Med 2006;174:499-507.

3 Devereux G, Barker RN, Seaton A. Antenatal determinants of neonatal immune responses to allergens. Clin Exp Allergy 2002;32:43-50. 
4 Martindale S, McNeill G, Devereux G, et al. Antioxidant intake in pregnancy in relation to wheeze and eczema in the first two years of life. Am J Respir Crit Care Med 2005;171:121-8.

5 Devereux G, Litonjua AA, Turner SW, et al. Maternal vitamin D intake during pregnancy and early childhood wheeze. Am J Clin Nutr 2007;85:853-9.

6 Shaheen SO, Newson RB, Henderson AJ, et al. Umbilical cord trace elements and minerals and risk of early childhood wheezing and eczema. Eur Respir $J$ 2004;24:292-7.

7 Litonjua AA, Rifas-Shiman S, Ly NP, et al. Maternal antioxidant intake in pregnancy and wheezing illnesses at 2 years of age. Am J Clin Nutr 2006;84:903-11

8 Farchi S, Forastiere F, Agabiti N, et al. Dietary factors associated with wheezing and allergic rhinitis in children. Eur Respir J 2003;22:772-80.

9 Antova T, Pattenden S, Nikiforov B, et al. Nutrition and respiratory health in children in six Central and Eastern European countries. Thorax 2003;58:231-6.

10 Forastiere F, Pistelli R, Sestini P, et al. Consumption of fresh fruit rich in vitamin C and wheezing symptoms in children. Thorax 2000;55:283-8.

11 Gilliland FD, Berhane KT, Li Y, et al. Children's lung function and antioxidant vitamin, fruit, juice, and vegetable intake. Am J Epidemiol 2003;158:576-84.

12 Hodge L, Salome C, Peat J, et al. Consumption of oily fish and childhood asthma risk. Med J Aust 1996;164:137-40.

13 Wijga AH, Smit HA, Kerkhof M, et al. Association of consumption of products containing milk fat with reduced asthma risk in pre-school children: the PIAMA birth cohort study. Thorax 2003;58:567-72.

14 Tabak C, Wiiga AH, de Meer G, et al. Diet and asthma in Dutch school children (ISAAC-2). Thorax 2006;61:1048-53.

15 Bolte G, Frye C, Hoelscher B, et al. Margarine consumption and allergy in children. Am J Respir Crit Care Med 2001;163:277-9.

16 Pistelli R, Forastiere F, Corbo G, et al. Respiratory symptoms and bronchial responsiveness are related to dietary salt intake and urinary potassium excretion in male children. Eur Respir J 1993;6:517-22.

17 Asher MI, Anderson HR, Beasley R, et al. International Study of Asthma and Allergy in Childhood (ISAAC): rationale and methods. Eur Respir J 1995:8:483-91.

18 Masson LF, McNeill G, Tomany JO, et al. Statistical approaches for assessing the relative validity of a food frequency questionnaire: use of correlation coefficients and the kappa statistic. Public Health Nutr 2003:6:313-21.

19 Craig LCA, McNeill G. Relative validity of a food frequency questionnaire for preschool children compared with a 4-day diet diary. Proc Nutr Soc 2006;65:39A.

20 Salam MT, Li Y, Langholz B, Gilliland FD. Maternal fish consumption during pregnancy and risk of early childhood asthma. J Asthma 2005;42:513-8.

21 Dunstan JA, Mori TA, Barden A, et al. Fish oil supplementation in pregnancy modifies neonatal allergen-specific immune responses and clinical outcomes in infants at high risk of atopy: a randomized, controlled trial. J Allergy Clin Immunol 2003;112:1178-84.

22 Henderson L, Irving K, Gregory J, et al. The National Diet and Nutrition Survey: adults aged 19-64 years. London: HMSO, 2003, http://www.food.gov.uk/ multimedia/pdfs/ndnsv3.pdf (accessed January 2007).

23 Boyer J, Liu RH. Apple phytochemicals and their health benefits. Nutr J 2004;3:5

24 Knekt P, Kumpulainen J, Jarvinen R, et al. Flavonoid intake and risk of chronic diseases. Am J Clin Nutr 2002;76:560-8.

25 Tabak C, Arts ICW, Smit HA, et al. Chronic obstructive pulmonary disease and intake of catechins, flavonols, and flavones. Am J Respir Crit Care Med $2001 ; 164: 61-4$.

26 Shaheen SO, Sterne JA, Thompson RL, et al. Dietary anti-oxidants and asthma in adults. Am J Respir Crit Care Med 2001;164:1823-8.

27 Woods R, Walters E, Raven J, et al. Food and nutrient intakes and asthma risk in young adults. Am J Clin Nutr 2003;78:414-21.

28 Butland B, Fehily AM, Elwood PC. Diet, lung function and lung function decline in a cohort of 2512 middle aged men. Thorax 2000;55:102-8.

29 Nair MPN, Kandaswami C, Mahajan S, et al. The flavonoid, quercetin, differentially regulates Th-1 (IFNgamma) and Th-2 (IL4) cytokine gene expression by normal peripheral blood mononuclear cells. Biochim Biophys Acta 2002;1593:29-36.

30 Department of Environmental Farming and Rural Affairs. National Food Survey. Trends in household nutrient intake, http://statistics.defra.gov.uk/esg/ publications/efs/2005/chapter5.pdf (accessed January 2007).

31 Thomas D. A study on the mineral depletion of the foods available to us as a nation over the period 1940 to 1991. Nutr Health 2003;17:85-115.

32 Thien FCK, Woods RK, De Luca S, et al. Dietary marine fatty acids (fish oil) for asthma in adults and children (review). Cochrane Database Syst Rev 2002;(2):CD0011283.

33 Schachter HM, Reisman J, Tran K, et al. Health effects of omega-3 fatty acids on asthma. Ottawa, Canada: University of Ottawa Evidence-Based Practise Center, 2004.

34 Cheung YB. Adjustment for selection bias in cohort studies: an application of a probit model with selectivity to life course epidemiology. J Clin Epidemiol 2001;54:1238-43.

35 Black PN, Sharpe S. Dietary fat and asthma: is there a connection? Eur Respir J 1997;10:6-12.

36 Seaton A, Godden DJ, Brown K. Increase in asthma: a more toxic environment or a more susceptible population? Thorax 1994;49:171-4.

37 Devereux G, Seaton A. Diet as a risk factor for atopy and asthma. J Allergy Clin Immunol 2005; 115:1109-17.

\section{LUNG ALERT}

\section{Severe infantile lower respiratory tract illness may be characterised by a reduced, rather than increased, immune response}

$\Delta$ Welliver T, Garofalo R, Hosakote Y, et al. Severe human lower respiratory tract illness caused by respiratory syncytial virus and influenza virus is characterized by the absence of pulmonary cytotoxic lymphocyte responses. J Infect Dis 2007; 195:1126-36.

$\mathrm{T}$ he pathogenesis of severe infantile respiratory illness due to respiratory syncytial virus (RSV) and influenza virus is not fully understood. Some evidence suggests there is an increased T lymphocyte and cytokine response to infection. However, this cross-sectional study found otherwise.

Nasopharyngeal secretions from 72 infants $<12$ months' of age, who had survived infection with RSV $(n=36)$ or influenza virus $(n=36)$, were examined for cytokine content. Post mortem lung specimens from 20 infants who had died of bronchiolitis caused by RSV $(n=9)$ or influenza virus $(n=11)$ underwent immunohistochemical staining to look for evidence of an immune response. In those who survived RSV infection, there was a significantly reduced immune response with regard to the classical T lymphocyte cytokines, compared with infants who had had influenza virus infection (interleukin 2 (IL2), $\mathrm{p}=0.04$; IL4, $\mathrm{p}=0.0001$; interferon $\gamma$, $\mathrm{p}<0.0001$; and IL17, $\mathrm{p}<0.0001$ ). Results from the group who had died from infection showed that there were substantially reduced amounts of CD4, CD8 and CD56 antigen-positive lymphocytes regardless of the infecting virus.

This study suggests that failure to develop a cytotoxic T lymphocyte immune response is key in the pathogenesis of viral respiratory illness in infants. These findings may be important in the development of possible treatments.

J Carter Senior House Officer, University Hospital of North Tees, Teesside; jeicarter@hotmail.com 